\title{
Vicissitudes of Aphasic Identity: Discourse Analysis Under James Paul Gee's Identity Framework
}

\author{
Nadir Ali ${ }^{1} \&$ Nadia Anwar ${ }^{1}$ \\ ${ }^{1}$ Department of English Language and Literature, University of Management and Technology Lahore, Pakistan \\ Correspondence: Dr Nadir Ali, Cheif Executive Naseem Medical Centre, Outfall Road, Sanat Nagar, Lahore, \\ Punjab, Pakistan. E-mail: dr_nadir_ali@yahoo.com
}

Received: June 26, 2018 Accepted: September 17, 2018 Online Published: December 29, 2018

doi:10.5539/ijel.v9n1p97 URL: https://doi.org/10.5539/ijel.v9n1p97

\begin{abstract}
Patients with post-stroke aphasia experience inability to communicate fluently, which is associated with an injury in the language areas of the brain. While much literature is available on the impact of aphasia suffered by the patient on family and important others, there is a dearth of data concerning the aspects of identity construction of the patient after the disastrous consequences of aphasia disorder. A discourse analytical framework was used by employing James Paul Gee's framework of identity perception with the aim of understanding the vicissitudes of identity in patients with aphasia. Data were obtained from semi-structured interviews of three participants and their partners. The interviews were video-recorded, transcribed and analysed using Paul Gee's Toolkit of doing discourse analysis; including four perspectives of identity driven by nature, institution, discourse and affinity. All these aspects were recognised as a negative construction of identity after aphasia disorder except some instances of positive construction in Affinity-Identity. The study concluded that post-stroke reconstruction of identity was an important challenge for the patients, family and healthcare services. In most of the cases, this reconstruction was negatively managed by the patients with aphasia and people surrounding them. Therefore, the present study has suggested the need to develop physical and virtual aphasia groups, such as aphasia clubs, aphasia tea houses and Facebook/WhatsApp aphasia groups, so that patients with aphasia can construct a positive Affinity-Identity within their affinity groups and general identity in other aspects of life. Moreover, a sound and effective training is recommended at social level to sensitize people about patients with special needs.
\end{abstract}

Keywords: identity construction, patient with aphasia, communication, discourse analysis, rehabilitation

\section{Introduction}

Aphasia is a communication disorder resulting from injury to the language areas of brain, causing impairments characterized by disorders in the ability to produce and comprehend language (Ahlsén, 2006; Ali, Rafi, Khan, \& Mahfooz, 2016, 2018). Cardio Vascular Accident (brain stroke) is the most common etiology of aphasia which constitutes almost $85 \%$ of all etiologies (Davidson, Howe, Worrall, Hickson, \& Togher, 2008; Maas et al., 2012). The incidence of aphasia after an attack of stroke is about $30 \%$ in the acute phase of disease (Dickey et al., 2010; Engelter et al., 2006; Laska et al., 2001; Law et al., 2009). A common type of aphasia disorder is expressive aphasia, the inability to fluently produce and express spoken or written language (Guina \& Guina, 2018) with intact comprehension, though in some other types of aphasia, patients may have impaired language comprehension.

Post-stroke survivors with aphasia face different problems and experience difficulties steering through their everyday life activities (Brady, Kelly, Godwin, Enderby, \& Campbell, 2016; Coppens, 2016; Mansur, Radanovic, Rüegg, Mendonça, \& Scaff, 2002; Plowman, Hentz, \& Ellis, 2012; Qamar, 2012). The available literature in the field of aphasiology on the quality of life among stroke patients shows that coping with post-stroke life for a patient with aphasia can be complicated and multilayered (Ch'Ng, French, \& Mclean, 2008; Hilari, Needle, \& Harrison, 2012; Khalid et al., 2016; Shyu, Maa, Chen, \& Chen, 2009; Sorin-Peters, 2003). Although, many studies in the field have explored the responses of partners (Cameron, Cheung, Streiner, Coyte, \& Stewart, 2011; Coombs, 2007; Ekstam, Tham, \& Borell, 2011; Persson, 2017; Sorin-Peters, 2003), caregivers and families (Cameron et al., 2011; Grigorovich et al., 2015; Hallé, Duhamel, \& Le Dorze, 2011) on the consequences of aphasia disorder, fewer have examined the effects of aphasia from the patient's perspective (Brown, Worrall, Davidson, \& Howe, 2010, 2015; Howe, 2017; Howe et al., 2012; Pound, Duchan, Penman, Hewitt, \& Parr, 
2007).

Most of the literature has explored the general difficulties faced by patients with aphasia, such as childcare, parenting, employment and return to work (Kim, Kim, \& Kim, 2014; Maaijwee et al., 2014; Teasell, McRae, \& Finestone, 2000; Wolfenden \& Grace, 2009), rather than their identity issues. In addition, the literature lack consistent evidence regarding social needs and identity issues of patients (R. J. P. Dalemans, de Witte, van den Heuvel, \& Wade, 2010; Manning, Hickey, MacFarlane, \& Franklin, 2017; Pike, Kritzinger, \& Pillay, 2017). Researchers reflect that aphasics not only suffer a brain infarction, but its consequences also agonize them with an "ego" infarction, i.e., the injury also has an influence on the "self" of the patient with aphasia (B. B. Shadden \& Agan, 2004; Wahrborg, 2008), which contributes to the potential damage to the identity of the patient (B. Shadden, 2005). Unfortunately, for a patient with aphasia, "Who am I now?" often does not correspond with "Who was I?", the existence before the disorder (Mackay, 2003). Consequently, the patient has to face post-aphasia identity crisis consistent with, and in addition to, the other limitations of the disorder. Shadden and Agan (2004) enunciate the definition of identity for a patient with aphasia as "a composite of roles, values and beliefs that are acquired and maintained through social interaction" (p 175) (B. B. Shadden \& Agan, 2004). We project our identities to other people during social interactions through communication and society approves or disapproves of the presented identity. In communication process we use language to create an image of others and it helps to create a positive or negative assessment of identity. When a social interaction and the subsequent discourse produced present a negative sense of one's self, the identity and self-respect of the subject suffers. A strong and stable identity is associated with 'well-being' and enhanced quality of life (Cooney, Murphy, \& O'Shea, 2009), which the circumstances seem to completely deny to the aphasia patients.

In the fast changing global world, identity is viewed by social scientists as an analytical tool to understand individuals, institutions and society. Identity has been understood in numerous ways in world literature. However, James Paul Gee (2000) prefers to focus on contextualizing how people act out and identify themselves rather than just how class, race and gender affect their identities. Paul Gee (2000) describes identity as 'being' who is acknowledged as a certain 'kind of person' within a given context that can change from time to time and place to place. This concept of having multiple identities is related to one's performance in society rather than to one's self. Gee (2000) states four ways to assess identity: Nature-Identity, a state developed from the forces in nature; Institution-Identity, a position authorized by authorities within the institutions; Discourse-Identity, an individual trait recognized in the discourse of individuals; and Affinity-Identity, experiences shared in the practices of 'affinity groups'. These four perspectives to view identity are interconnected in complex ways, rather than existing as distinct categories, and emphasize on how these identities are constructed and function for a specific person in a given context (Gee, 2000).

A coherent sense of identity of a person is established and modified through communicative interactions. Identities, as described by Goodwin (1987), are established through constructed talks. Goodwin (1987) argues that, "people design communication in such a way as to bring into play selected identity relationships among the conversational participants', so the choice of words used, topic of interest, or discourse organization during the communicative activity provide important insights into one's identity (Goodwin, 1987). Speech language pathologists (SLP) invoke patients' identity when they are being asked to narrate history of disease and consequences of stroke.

With the onset of disease, patient's identity is stormed and destabilized by many factors. The patient with aphasia faces changes in physical abilities, roles in society, relationships with others and performance in social life. For them, post aphasia circumstances, personal experiences and attitudes of other members of community are no longer consistent with their premorbid identity. Their immediate others and healthcare providers introduce a new identity to them (Mackay, 2003; Shadden \& Agan, 2004). The feelings of disempowerment, along with the inability to communicate, worsen the situation forcing them to acquire a dependent status which not only inhibits their identity development but also undermines it.

In this research, the focus is to explore how patients with aphasia have to face vicissitudes of identity in their social context. These kinds of identities are interlinked as a unified whole, in case of individual acts carried out in a specific context. However, it is worth exploring which aspect of identity predominates in aphasic patients.

\subsection{Research Questions}

In this study the following questions are asked:

- Do post-stroke patients with aphasia face vicissitudes of identity in their social context?

- Do these changes encompass all four aspects of identity as postulated by Paul Gee (2000)? 
- Do these altered identities affect the patients with aphasia positively?

\subsection{Research Objective}

In order to find answers to the research questions, the following objectives have been formulated:

- Investigate the identity construction of the patients with aphasia after an episode of stroke by understanding the trajectory of effects on different aspects of their identities.

- Identify the changes constitutive of all four aspects of their identity

- Highlight the positive effects on the patient's aphasic health during identity construction in the social context.

\section{Method}

\subsection{Theoretical Underpinning}

Considering Gee's analytical lens of viewing identity, a qualitative study, using his Toolkit (2010) for doing discourse analysis (Gee, 2010), was conducted with the aim of understanding vicissitudes of identities of patients with aphasia. By obtaining data from semi-structured interviews as the research instrument, this study focused on the dialogue generated by the patients in a group discussion with the participants and the researcher, including amplification and inputs from their partners.

The identities under investigation are: Nature-Identity (N-Identity), Institutional-Identity (I-Identity), Discourse-Identity (D-Identity) and Affinity-Identity (A-Identity). The researchers have described how each kind of identity perspective can be applied to one single example i.e., the identity construction of the patient. It is the force of nature that contributes to shaping of a patient's identity as being "aphasic" (N-Identity), who struggles to strive and achieve an identity by gaining a position in the society (I-Identity). The patient is known by his individual accomplishments in an institution which are recognized by others during social interactions (D-Identity). Further, s/he tries to seek solidarity with a group where s/he has had a certain sort of affinity (A-Identity). These kinds of identities are interlinked and co-exist, as discussed above. However, it is worth exploring the identity that predominates in these patients (Gee, 2000).

\subsection{Participants}

Initially, six patients with expressive aphasia, also known as Broca's aphasia, were selected conveniently from two institutions of speech therapy of Lahore, Pakistan. Three out of six participants were declined from the study due to the reasons discussed later and ultimately three adult right-handed Urdu/Punjabi bilingual male patients of moderate to severe Broca's aphasia were continued with the study. The field work was done by the primary researcher who also tried to select female patients as the participants of the study but unfortunately could not succeed. Although the researcher did find a female patient for this study, her husband did not allow her to participate, so the study had to be conducted with the male participants only who were selected conveniently from an aphasia treatment group of pre-diagnosed patients. They were evaluated and diagnosed under the expert supervision of a consultant speech language pathologist. One important concern during the sampling process was to explain to the potential patients, their partners or caregivers whether their participation in the study would help them in any way, physically or psychologically. One of the patients accepted to attend the interview sessions but he withdrew at the eleventh hour mainly because he was under a severe psychological burden due to the physical limitations that had been developed after the brain hemorrhage. His psychological trauma did not allow him to attend the session.

The participants finally selected for the study were three patients with Broca's aphasia. One of these three participants had received and two of them were receiving some type of aphasia rehabilitation therapy along with medical treatment at the time of interview. The selected participants were able to comprehend questions of the interview and were able to give their consent to be a part of the study. The inclusion criteria stipulated a good comprehension of the Urdu/ Punjabi language, prior to the onset of brain injury, with at least 6 months post-stroke aphasia. Lower than moderate levels of aphasia and all speech disorders other than expressive aphasia formed the exclusion criteria of the study. Patients with poor prognosis of disease and having severe psychological problems were also not considered for the study.

\subsection{Demographics of the Study Participants}

Demographics were obtained from the participants, as seen in table 1 . One of the participants $(n=1)$ of this study was the subject of a previous study conducted by the primary researcher. He participated actively and enthusiastically in the study with a sense of responsibility. The second participant $(n=2)$ had had no formal education and showed qualms about the study by raising question on its utility in bringing any betterment to his 
condition. The third participant $(\mathrm{n}=3)$ was a medical graduate and his superadded psychological issues had aggravated the consequences of aphasic disorder. Hence, the present study was carried out with the help of three participants ranging from 38 to 57 years old with moderate to severe Broca's aphasia.

Table 1. Demographics of the participants

\begin{tabular}{llll}
\hline Participants & Age & Years Since Stroke & Gender \\
\hline $\mathrm{n}=1$ & 38 & 5 & $\mathrm{M}$ \\
$\mathrm{n}=2$ & 57 & 12 & $\mathrm{M}$ \\
$\mathrm{n}=3$ & 41 & 2 & $\mathrm{M}$ \\
\hline
\end{tabular}

Note. " $\mathrm{n}$ " is number of participants; "M" is male.

These demographics were based on unintentional selection.

\subsection{Data Collection}

The participants were informed about the purpose of the study prior to the interview session for the data collection. All the participants provided informed consent for the study. The primary researcher conducted the session of data collection through semi-structured interviews with the selected patients. The participants were asked if they preferred their partners' presence in the sessions of interview, to which all the participants showed desire, though it was not the requirement of the inclusion criteria of this study. With the help of their partners, the participants communicated their own experiences. Each semi-structured interview session was video-recorded for transcription purposes. The participants and their partners consented to being video-recorded during the interview.

The topics for semi-structured interview were presented to the participants in the form of general questions, as seen in table 2.

Table 2. The general questions asked in semi-structured interview

\begin{tabular}{l}
\hline Questions for semi-structured interview \\
\hline 1 What type of changes do you feel in your behavior and mood after the stroke episode? \\
2 What is your perception about the rehabilitation of your language inability and its progress? \\
3 What type of activities do you have to engage with and in what way? \\
4 What were your job activities and social life engagements before this limitation? \\
5 What type of relationships do you have with your partners and important others? \\
6 How do you compare these relations with the pre-stroke circumstances and how have these circumstances changed? \\
\hline
\end{tabular}

These open-ended questions were prompted and the participants' choice of answering them and their flexibility to alter the topic was ensured, considering their functional consequences of the ailment. Although the participants were encouraged to share their experiences and stories, they showed varied ability of verbal output to communicate their expressions in their replies, ranging from partially fluent to responding in a very limited way, requiring the help of their partners to fill in their blanks. The researchers reconfirmed and rechecked timely the point of views and insights of the patients by consulting their partners' opinion about their expression so that the misinterpretation of the messages could be avoided. This strategy, of consulting the partners, made the dataset, obtained from the semi-structured interviews, a more valid representation of the expressions of the patients.

\section{Data Analysis}

Discourse analysis (DA) is an ideal instrument for exploring Gee's (2000) four perspectives of identity in the patients with aphasia (Gee, 2000). DA is particularly appropriate for the dataset gathered from the participants whose verbal communication is impaired, which forces them to seek help from other sources of communication, e.g., body language, like gesture, gaze, or other visual cues, like written expressions etc., to complete their communicative process that plays an important role in identity construction. Gee's Toolkit (2010) for DA particularly provides different means to explore identity construction in the context of figured worlds.

The primary researcher transcribed the video recordings of the semi-structured interviews. All the transcriptions were rechecked by the co-researcher, a Ph.D. scholar, to ensure the accuracy of the transcribed data. The primary researcher qualitatively analyzed the transcription of each verbal and nonverbal expression of the participants 
and their partner's input by using the relevant ones from all 27 tools for doing discourse analysis presented by Gee (2010). The procedure of data analysis was started with the transcript of the $1^{\text {st }}$ participant $(n=1)$, followed by the other transcripts, first individually and then combined. In order to recognize the indices of identity within the dataset, the researchers cycled through the recorded material and transcripts to identify which aspect of identity construction was discovered. Once the relevant segments were identified, they were reviewed further for analysis to determine the function of the aphasic discourse, which, in turn, was associated with the identity construction of the patients with aphasia.

All steps of the DA procedure were followed by the primary researcher. If there was any confusion about the point of views and insights of the participant, the researcher reconfirmed and rechecked by consulting the partners' opinion about the intended meaning of the participants' expressions in order to avoid the misinterpretation of the message. The procedure ensured that no important meaning units were underestimated or missed. The primary researcher had to set a criterion in order to synchronize the specific instances from the dataset to the relevant tool. For this, different options were considered with the co-researcher, until a consensus was reached (Husbands, Jowett, Barton, \& Coast, 2017) to ensure the integrity and credibility of the findings.

\subsection{Validation of Data Analysis}

Once the dataset was analyzed and interpreted, the primary researcher referred back to the video-recordings and transcripts to clarify and verify the evidence of the participants' behaviours and interpretations. It was evident that no conflicts were noted with the final interpretation of the data analysis. A poster presentation for the research project was arranged to further validate the preliminary findings and analysis of research data. The findings and preliminary results were presented to a group of qualitative researchers and to the project supervisor for critical comments and active feedback to assess whether the findings of the study were consistent with the dataset. The supervisor inspected the initial findings, reviewed the dataset table, and appreciated the findings of the study based on her previous experience in the field.

\subsection{Ethical Considerations and Approval}

Ethical approval for the present study was granted by the Ethical Review Committee of the Department of English Literature and Language, University of Management and Technology, Lahore. The researchers followed the ethical considerations of the framework of Health and Social Care, particularly with regard to interview study (Walker, 2007). These considerations include careful planning for dealing with the interview discussion and the preparation of the documents; written consent for the participants, a brief description of the study perspectives and a pre-determined question format. Ethical consideration during interview discussions involved drawing attention to points which were not still clear, clarifying misunderstandings, if any, considering any sign from the participant to have a break or quit the activity, ensuring anonymity, and taking consent for mentioning their affiliation with institutions, if required (Walker, 2007).

\section{Results}

The model of having multiple identities, in relation to the patient's performance in society, was observed and all four ways of assessing identity (Gee, 2000) were perceived. Considering the aim of the study, the researcher found the relevant aspects of identities of the patients with aphasia and presented them in detail with examples from dataset using Gee's Toolkit, as seen in table 3.

Table 3. Four aspects of identity of the post-stroke patients with aphasia

\begin{tabular}{|c|c|c|c|c|}
\hline & Identity Type & $\begin{array}{l}\text { Source of } \\
\text { Power }\end{array}$ & Gee's Tool & Examples from Data \\
\hline \multirow[t]{9}{*}{1} & \multirow{9}{*}{$\begin{array}{l}\text { N-Identity (a } \\
\text { state) }\end{array}$} & \multirow{9}{*}{$\begin{array}{l}\text { Force in } \\
\text { nature }\end{array}$} & Tool 2: The Fill in Tool & Fails to utter and gives agonised facial expressions $(n=1)$ \\
\hline & & & Tool 3: The Making Strange Tool & In reply to, 'are you a doctor?', ...ni uon. (no, I am not) $(\mathrm{n}=3)$; \\
\hline & & & Tool 4: The Subject Tool & $\begin{array}{l}\text {...bara saal goonga (have not been able to speak since the last } \\
12 \text { years) }(n=2)\end{array}$ \\
\hline & & & Tool 5: The Intonation Tool & $\begin{array}{l}\text { Sang a melody with a change of one word 'mere' }(m y) \text { with } \\
\text { 'tere' (your)...tu 'tere' endegii ey...(you are 'your' life) }(\mathrm{n}=1)\end{array}$ \\
\hline & & & $\begin{array}{l}\text { Tool 7: The Doing and not Just } \\
\text { Saying Tool }\end{array}$ & Tears in eyes while staring at his right hand $(n=1)$ \\
\hline & & & Tool 19: The Connections & Replying to a question, he draws a cross on a page \\
\hline & & & Building Tool & $(\mathrm{n}=3) ; \ldots$ mery bachy! (my children!) $(\mathrm{n}=3)$ \\
\hline & & & Tool 21: The Sign Systems and & ...tu tere endegii ey...(you are your life) $(\mathrm{n}=1)$; draws \\
\hline & & & Knowledge Building Tools & Pakistani flag $(n=2)$; draws a stethoscope $(n=3)$ \\
\hline
\end{tabular}




\begin{tabular}{|c|c|c|c|c|}
\hline \multirow[t]{7}{*}{2} & \multirow[t]{7}{*}{$\begin{array}{l}\text { I-Identity (a } \\
\text { position) }\end{array}$} & \multirow[t]{7}{*}{$\begin{array}{l}\text { Authorities } \\
\text { within } \\
\text { institution }\end{array}$} & Tool 3: The Making Strange Tool & $\begin{array}{l}\text {...ak, doo, teen yaad ...dafter sy nkala (help me learn } \\
\text { counting...they will fire me) }(\mathrm{n}=1) ; \text {...ephazia hy (I have } \\
\text { aphasia) }(\mathrm{n}=3) ; \text {...tu ram ...kam ni (you take rest, don't work) } \\
(\mathrm{n}=2)\end{array}$ \\
\hline & & & Tool 4: The Subject Tool & $\begin{array}{l}\text {...pashen kesy chek (how will you check your patients) }(\mathrm{n}=3 \text { ); } \\
\text { his boss called his wife and said...uda ke faida! (what is his } \\
\text { benefit!) (n-1) }\end{array}$ \\
\hline & & & Tool 5: The Intonation Tool & ...baat samj (clients understand me) $(\mathrm{n}=2)$ \\
\hline & & & Tool 8: The Vocabulary Tool & $\begin{array}{l}\text {...tut tut tut, beechara }(\text { what an unlucky guy })(\mathrm{n}=2) ; \ldots \text { Allah } \\
\text { keram kery ga }(\text { God will help you })(\mathrm{n}=3)\end{array}$ \\
\hline & & & $\begin{array}{l}\text { Tool 9: The Why this Way and } \\
\text { Why not that Way Tool }\end{array}$ & $\begin{array}{l}\text {...namb lik do (write your cell number) }(\mathrm{n}=1) ; \ldots \text { peshen ko lik } \\
\text { de (I write instructions for my patients) }(\mathrm{n}=3)\end{array}$ \\
\hline & & & $\begin{array}{l}\text { Tool 11: The Topic and Themes } \\
\text { Tool }\end{array}$ & $\begin{array}{l}\text {...wo tu wesy aata (he comes to his workplace just for } \\
\text { nothing) }(\mathrm{n}=3)\end{array}$ \\
\hline & & & $\begin{array}{l}\text { Tool 16: The Identities Building } \\
\text { Tool }\end{array}$ & $\begin{array}{l}\text {...sher bano }(\text { be brave })(\mathrm{n}=1) ; \text {.. mushkil ni oti (there will be } \\
\text { no hurdle })(\mathrm{n}=2) ; \text {... bara saal ho gaye (it's been } 12 \text { years) } \\
(\mathrm{n}=2)\end{array}$ \\
\hline \multirow[t]{6}{*}{3} & \multirow{6}{*}{$\begin{array}{l}\text { D-Identity } \\
\text { (an individual } \\
\text { trait) }\end{array}$} & \multirow{6}{*}{$\begin{array}{l}\text { Discourse } \\
\text { of } \\
\text { individuals }\end{array}$} & $\begin{array}{l}\text { Tool 7: The Doing and not Just } \\
\text { Saying Tool }\end{array}$ & ...gaak chaly jaty (customers go back) $(\mathrm{n}=2)$ \\
\hline & & & $\begin{array}{l}\text { Tool 16: The Identities Building } \\
\text { Tool }\end{array}$ & $\begin{array}{l}\text {...ham in ko kam nhi kehty (we don't ask him to work), said } \\
\text { his brother ( } \mathrm{n}=1) ; \text {... bechara bohat mehneti tha (he was very } \\
\text { hard working, poor soul), said his brother ( } \mathrm{n}=1) ; \text {... sare } \\
\text { zindegi bohat struggle ke unhon ny... ab gher beth gaye hein } \\
\text { (he struggled hard throughout life, now he is stuck at home), } \\
\text { said his wife ( } \mathrm{n}=2 \text { ) }\end{array}$ \\
\hline & & & Tool 19: The Connections & ...reshty daron sy kam milta hy (now he meets rarely with \\
\hline & & & Building Tool & $\begin{array}{l}\text { relatives), said his brother }(\mathrm{n}=1) ; \ldots a b \text { tu shadeyon pe aaty } \\
\text { jaty hein (now he attends family marriages), said his wife } \\
(\mathrm{n}=2) ; \text {...un ky friends bhi ab nhi aaty (his friends don't come } \\
\text { any more), said his wife }(\mathrm{n}=3)\end{array}$ \\
\hline & & & $\begin{array}{l}\text { Tool 21: The Sign Systems and } \\
\text { Knowledge Building Tool }\end{array}$ & His wife started weeping, during discussion $(n=3)$ \\
\hline & & & $\begin{array}{l}\text { Tool 23: The Situated Meaning } \\
\text { Tool }\end{array}$ & $\begin{array}{l}\text {...in ko dekhte hon aur pher bachon ko dekhte hon tu bohat } \\
\text { dukh hota hy (I feel very sad when I look at him and then at } \\
\text { the children), said his wife ( } \mathrm{n}=3 \text { ) }\end{array}$ \\
\hline \multirow[t]{4}{*}{4} & \multirow[t]{4}{*}{$\begin{array}{l}\text { A-Identity } \\
\text { (an } \\
\text { experience) }\end{array}$} & \multirow[t]{4}{*}{$\begin{array}{l}\text { Practice of } \\
\text { affinity } \\
\text { groups }\end{array}$} & $\begin{array}{l}\text { Tool 15: The Activities Building } \\
\text { Tool }\end{array}$ & $\begin{array}{l}\text { He used to go to church and pray...Hallelujah }(\mathrm{n}=1) ; \text {...ef be } \\
\text { achi (Facebook is good) }(\mathrm{n}=3) \text {; ti pass kerta wa sai (I pass } \\
\text { time on WhatsApp) }(\mathrm{n}=3)\end{array}$ \\
\hline & & & $\begin{array}{l}\text { Tool 17: The Relationships } \\
\text { Building Tool }\end{array}$ & $\begin{array}{l}\text {...beti khush kerte...khana...peyary baba (my daughter makes } \\
\text { me happy... gives me food and calls me dear father) }\end{array}$ \\
\hline & & & & $\begin{array}{l}(\mathrm{n}=1) ; \text {. . aik goonga doost acha (one of my friends, who is } \\
\text { dumb, is very nice) }(\mathrm{n}=2) ; \text {...ni sunty bat (they don't listen to } \\
\text { me, now) }(\mathrm{n}=2) \text {; replying to, should there be aphasia club, he } \\
\text { said han (yes) }(\mathrm{n}=3) \text {; in another question, he said ...ef be goup } \\
\text { bnao (I will make a Facebook group) }(\mathrm{n}=3)\end{array}$ \\
\hline & & & Tool 26: The Figured Worlds Tool & $\begin{array}{l}\text {...sab theek hy (everything is alright) }(\mathrm{n}=2) ; \ldots \text { insan } o \text { (we are } \\
\text { also human })(\mathrm{n}=2)\end{array}$ \\
\hline
\end{tabular}

\subsection{Nature-Identity}

All three participants of the study were living their normal lives and enjoying their natural capacity in all respects, before the episode of aphasia disorder. None of them were able to return to their premorbid N-Identity, which describes the state of a person, defined by and developed from forces in nature (Gee, 2000). A crucial part of an aphasic state under N-Identity pertained to how the patient perceived his own being after developing stroke to describe the identity that he did not accomplish but was thrust upon him. The forces in nature controlled the circumstances regarding ailment, on which the society and he himself had no power or control.

The unit 1, "Language and Context" of Gee's Toolkit (2010), defines "context" as the physical setting in which the act of communication takes place and also includes everything in the setting such as gesture, eye gaze and movements of participants, and shared personal and cultural knowledge of participants involved in 
communication (Gee, 2010). With the context in mind, "The Fill in Tool" (Tool 2) helped to analyse N-Identity, when the participant $(\mathrm{n}=1)$ showed agonised and helpless facial expressions and could not utter a single word to make his response. His struggle showed that his premorbid N-Identity had altogether changed and nature forced him to reconstruct an aphasic identity. Similarly, the vicissitudes of N-Identity were observed considering "The Making Strange Tool" (Tool 3) which helped analyse how the patient tried to act as an outsider. Although still a doctor, the participant $(n=3)$ refused to affirm this identity in response to one of the questions. The participant, considered as normal in medical contexts, was tagged as an aphasic, who not only changed his identity, but also made himself an outsider. "The Subject Tool" (Tool 4), which describes how subjects consider themselves, also captured the instances of altered N-Identity from the dataset, when the participant $(\mathrm{n}=2)$ labelled himself as bara saal goonga (have not been able to speak since the last 12 years). Altered N-Identity was also perceived in the instances by using "The Intonation Tool" (Tool 5). This was reflected when the participant (n=1) sang a melody with a change of one word 'tere' (your) instead of 'mere' (my) in a verse of a classical song as, tu 'tere' endegii ey (you are 'your' life). The stress on the word 'tere' (your) described his feeling of exclusion from the natural domains of life. Conscious denial of pre-aphasic identity is also suggestive of the institutional influence on the subject in question.

The unit 2, "Saying, Doing, and Designing" of Gee's Toolkit (2010), describes how language can accomplish a range of functions apart from conveying information. The Tool 7, "The Doing and Not Just Saying Tool", of this unit 2, which not only focuses on 'what is being said' but also on 'what is being done' (Gee, 2010), identified the instances from the dataset with regard to the reconstructing of N-Identity, e.g., question about patients' pre-aphasic and post-aphasic behaviour and mood. The participant $(\mathrm{n}=1)$ unsuccessfully and desperately tried to utter in response to the question but failed. The researchers observed that he was staring at his right hand with tears in his eyes, as he suffered right hemiplegia along with aphasia. The containment of expression and feelings to gestures appeared to have shaken the very soul of the participant.

The unit 3, "Building Things in the World", describes the reflexive nature of context to shape the language, but, at the same time, be shaped by it. By using Tool 19, "The Connections Building Tool", which emphasises connection or disconnection with possessions or relations (Gee, 2010), the researchers found that the participant $(\mathrm{n}=3)$ had developed the feelings of nothingness when he, holding a pen, drew a cross on the page while replying to the question about his relationships with his partners and important others. The participant $(n=3)$ uttered many a times, mery bachy (my children) and tried to maintain his N-Identity of being a father of two kids even after the unavoidable episode of stroke. The researchers used Tool 21, "The Sign Systems and Knowledge Building Tool", which highlights the ways in which language privilege or malign sign systems, to evaluate the participant's $(\mathrm{n}=1)$ N-Identity construction through his song, in which he sang tu tere endegi ey (you are 'your' life), instead of singing tu mere zindagi hy (you are 'my' life). The same tool also highlighted their reconstruction of N-Identity, when one of the participants $(n=2)$ drew Pakistani flag and the other participant $(n=3)$ drew a stethoscope to recognise themselves with their premorbid N-Identities. Signs and symbols exist in abstract spaces, which cannot easily be touched by the physicality of trauma. The drawings are a way to substantiate those identities which are still maintained in their pure form in the conscious recesses of the minds of the participants.

\subsection{Institutional-Identity}

$\mathrm{N}$-Identity always collapses into other kinds of identities, which gain their force as identities from other sources such as institutions, discourse and affinity groups (Gee, 2000). Once the patient was diagnosed as aphasic and became the client of a medical professional, who attempted to remediate and monitor the disorder, the patient started reconstructing I-Identity, immediately after diagnosis. However, what remained to be seen was whether the reconstructed identity refurbished his self-esteem or further deteriorated his idea of the self. It was institution and authorities that gave the patient a certain kind of aphasic identity. As the patient's role was officially defined by medical discourse and practices related to aphasic patients, his N-Identity and I-Identity mutually sustained the consequences. He was socialized and regarded as a representative aphasic patient (in words and deeds) by the medical institution. Once the patients received some type of rehabilitation for speech disorder, they were keen to engage in their previous work and reconstruct their I-Identity, but the institution did not allow that to happen, and pushed them back to their pre-rehabilitation status. So we could observe a kind of push and pull of identities where each identity tried to dominate the other. Here an important question arises about the utility of the rehabilitation centres, which, without proper social and institutional support, may not be able to achieve their targets.

By using the Tool 3, "The Making Strange Tool" of Gee's Toolkit (2010), the researchers analysed that the participant's (n=1) I-Identity reconstructed temporarily after returning to his work. For example, the participant 
$(\mathrm{n}=1)$ asked his speech therapist $a k$, doo, teen yaad...dafter sy $n k a l a$ (help me learn counting...they will fire me). The participant $(\mathrm{n}=3)$ had learnt to accept his aphasic identity with an acceptance among his colleagues of his condition, ephasia hy (I have aphasia). At his work place, the participant $(\mathrm{n}=2)$ was asked not to work and take rest even after receiving speech rehabilitation for aphasia disorder, e.g., tu ram...kam ni (you take rest, don't work). This amounts to pushing back the participant to what he desires to leave behind.

The dataset was analysed to locate post-stroke I-Identity construction using "The Subject Tool" (Gee's Tool 4) and the instances were found where the participant $(\mathrm{n}=3)$, in his workplace, was chosen as a subject, e.g., his colleague asked him pashen kesy chek (how will you check your patients). In another example of isolating them as a subject, the participant's ( $\mathrm{n}=1$ ) boss called his wife and said...uda ke faida! (what is his benefit!). The use of "The Intonation Tool" (Gee's Tool 5) in the analysis revealed that the participant's (n=2) pitch contour contributed to his message delivery and he said baat samj (clients understand me). Similarly, the researchers analysed the dataset using "The Vocabulary Tool" (Tool 8) through which negative I-Identity construction was observed. The clients of the participant $(n=2)$ were frequently using the words or expressions that influenced his positive construction of identity, e.g., for him $(\mathrm{n}=2)$ it was tut tut tut, beechara (what an unlucky guy), and for the participant $(\mathrm{n}=3)$ Allah keram kery ga (God will help you).

The participant $(\mathrm{n}=1)$ used to write down his message using a copy and a pen to establish his communication with colleagues and clients in his office. The researchers used Gee's Tool 9, "The Why This Way and Why Not that Way Tool", to analyse the data to understand how the participants constructed their I-Identity. For example, the participant ( $\mathrm{n}=1$ ) was asked namb lik do (write your cell number), and the participant $(\mathrm{n}=3)$ said peshen ko lik de (I write instructions for my patients). Finding alternative means of expression seemed to have worked out in some cases. However, the acceptance of that expression was out of sight. "The Topic and Themes Tool" (Tool 11) helped to analyse the instances where the co-workers of the participant $(n=3)$ were contributing in constructing his I-Identity negatively through content and themes of their sentences. For example, his colleagues were of the view that wo tu wesy aata (he comes to his work place just for nothing). "The Identity Building Tool" (Tool 16) helped to analyse data to understand what identities the aphasic patients invited others to take up and what type of socially recognisable I-Identity they tried to enact. For example, the colleagues of the participants $(n=1)$ were habitually asking him sher bano (be brave), and the participant $(\mathrm{n}=2)$ used expression mushkil ni oti (there will be no hurdle) with clients in his workplace. At the same time, he was also accepting that bara saal ho gaye (it's been 12 years), struggling with adverse circumstances. This instance reflects how even the very act of encouragement becomes a means to implicate the deficiency of the subject.

\subsection{Discourse-Identity}

The third aspect of identity that the patients with aphasia construct was D-Identity; the discursive practices of the people accompanying the patients which help to build their negative D-Identity. This aspect of identity was actively defined by others in their discourse. The patients ultimately became an embodiment of what the relatives talked about them, how they treated them and how they interacted with them. Hence, the D-Identity became an imposition on the patients, due to which they suffered. The dataset was ripe with examples from quotations of the relatives of the patients, who played a crucial role in building up their negative identity. Their words for the patients such as beychara (unfortunate / helpless creature) revealed how they viewed the patient.

By using the Tool 7, "The Doing and Not Just Saying Tool”, of Gee's Toolkit (2010), the researchers analysed that the participant's ( $\mathrm{n}=2) \mathrm{D}$-Identity had been reconstructed as a part of discursive practices of people, e.g., he said gaak chaly jaty (customers go back) because he was unable to reply to them properly. Without expressing or saying anything, the client's action created the meaning (his new identity) for him. Other examples also mentioned their D-Identity construction e.g., by using "The Identities Building Tool" (Tool 16), the researchers analysed the instances where one of the participant's ( $(\mathrm{n}=1)$ brother said, ham in ko kam nhi kehty (we don't ask him to work). In another example the same participant's brother, while describing his past history, said, bechara bohat mehneti tha (he was very hard working, poor soul). Again, the same type of expressions of their partners were observed for other participants as well, e.g., the participant's $(\mathrm{n}=3)$ wife said, sare zindegi bohat struggle ke unhon ny...ab gher beeth gaye hein (he struggled hard throughout life, now he stays at home).

The researchers used "The Connections Building Tool" (Tool 19) to assess the D-Identity of the participants, e.g., in the interview discussion, the participant's $(\mathrm{n}=1)$ brother explained his everyday life activities and said, reshty daron sy kam milta hy (now he meets rarely with relatives). Similarly, the participant's $(\mathrm{n}=3)$ wife said, un $\mathrm{ky}$ friends bhi ab nhi aaty (his friends don't come any more), whereas the participant's ( $\mathrm{n}=2$ ) wife explained, $a b$ tu shadeyon pe aaty jaty hein (now he only attends family marriages). "The Sign Systems and Knowledge Building Tool" (Gee's Tool 21) also helped the researchers to analyse negative construction of D-Identity when the 
participant's $(\mathrm{n}=3)$ wife started weeping during interview discussion about her husband which showed the way aphasic discourse was constructed to destabilize the lives of the affectees. The researchers also used "The Situated Meaning Tool" (Tool 23) to describe their D-Identity construction, e.g., one of the participant's (n=3) wife said in ko dekhte hon aur pher bachon ko dekhte hon tu bohat dukh hota hy (I feel very sad when I look at him and then at the children), which created a glaring aphasic discursive identity for the involved. Also, the comparison categorically draws a line between what the subject was able to do and what he could not do in his present condition.

\subsection{Affinity-Identity}

The $4^{\text {th }}$ perspective on identity is the A-Identity; the distinct social practices of an affinity group of the patients create group affiliation and help in building their A-Identity. The researchers analysed the specific examples from the dataset using Paul Gee's Toolkit (2010) that mentioned reconstructing A-Identity (Gee, 2010).

By using the Tool 15, "The Activities Building Tool", which describes what type of activities are enacted by what social groups, the researchers observed that the participant's $(n=1)$ A-Identity had been reconstructed after returning to his affinity group. For example, the participant $(n=1)$ used to go to Church and found affiliation through praying Hallelujah. One of the participants $(\mathrm{n}=3)$ declared during the interview that ef be achi (Facebook is good), where he practiced chatting with his affinity group. The other participant $(n=3)$ also shared similar views regarding affinity group, e.g., he said, ti pass kerta wa'sai (I pass some time on WhatsApp). The researchers also used Tool 17, "The Relationship Building Tool", which considers developing relationships through lexical choices. For example, in the dataset, one of the participants $(n=1)$ was smiling while discussing his daughter and said, beti khush kerte...khana...peyary baba (my daughter makes me happy... gives me food and calls me dear father). The participant $(\mathrm{n}=2)$ also showed his affiliation with one of his aphasic friends and said, aik goonga doost acha (one of my friends, who is dumb, is very nice). In another instance, he seemed troubled by his family members, who ni sunty bat (don't listen to me, now). Replying to one of the questions about making an aphasia club, the participant $(\mathrm{n}=3$ ) said han (yes), in another question, he replied, ef be goup bnao (I will make a Facebook group).

The participants' A-Identity construction was viewed during the data analysis by using "The Figured Worlds Tool" (Tool 26) from unit 4 of Gee's Toolkit (2010). Tool 26 draws on different theoretical perspectives to figure out what world view assumes the meaning of words and invites others to assume the same. The researchers analysed the instances from the dataset where one of the participants $(\mathrm{n}=2)$ declared that sab theek hy (everything is alright) and insan o (we are human). Whether the participant really meant to convey his satisfaction with the state of affairs remained questionable; however, there was an attempt for self-reassurance that might help him to go on with life.

\section{Discussion}

A wealth of literature is available about the effects of this disastrous ailment and its effects on different aspects of identity (Bokhour, Powel, \& Clark, 2007; Emmelhainz, 2012; Golub, Rendina, \& Gamarel, 2013). Particularly, the studies have described the challenges of aphasic identity reconstruction, after an acute attack of stroke and head injury (Ellis-Hill, Payne, \& Ward, 2000; Lapadatu \& Morris, 2017; Muenchberger, Kendall, \& Neal, 2008; Musser, Wilkinson, Gilbert, \& Bokhour, 2015; Walder \& Molineux, 2017). Greenhalgh et al., (2017) and others define the patients' most important achievement as learning to recite a new story for their own sake, which integrates their specific post-traumatic limitations of the disorder (Greenhalgh \& Goozner, 2017). In the present research, the participants narrated, rather created, their new stories as reflected in their talks about post-stroke changed identity, which, in most of the cases, proved negative.

The impaired language and distorted communication of the participants were important factors that had drastically influenced their identity. The focus of the analysis was not on practicing the linguistic elements of the participants, who had impaired communication competence, but the stress was on what they wanted to communicate in the given context; the voice of the patients with aphasia. As active members of society, parents, and partners, these limitations forced the participants to reconstruct their identity. This reconstruction of identity was dependent on several aspects, including the severity level of the disorder (Thomas \& Lincoln, 2008), their family support (Eriksson \& Svedlund, 2006), relationships with friends, and their social context in general, which provided them abilities and further prompted them to construct new identities. This post-stroke identity construction in the social context was impacted by waves of depression, which is a common feature in aphasia disorder (Bluvol, 2003; Khalid et al., 2016; Musser et al., 2015; Thomas \& Lincoln, 2008). The participants of this study showed their depression on different occasions during the interviews that was closely tied to their disease consequences and responses of their important others to the disease, for example, whenever the 
participant $(\mathrm{n}=1)$ failed to utter some verbal expression that he wanted to, the agonized facial expression showed his extreme disconcertion about his condition. This phase of depression negatively influenced his and other participants' identity construction after aphasia.

The analysis of semi-structured interviews with the participants and their important others revealed how post-stroke aphasia disorder could bring changes in all four perspectives of identity, i.e., nature-identity, institution-identity, discourse-identity and affinity-identity (Gee, 2000) and how these identities negatively, and in few instances, positively influence the affectees during the identity reconstruction. The researchers analyzed how the participants and their partners provided emotionally palpable accounts during their interactions to show the impact of aphasic consequences. They also underscored how others in the society perceived their identity in the context. Consistent with the results of a previous research study by Musser et al., (2015) the participants of this study also revealed a few positive aspects of their identity reconstruction. Nevertheless, in the majority of the cases, the participants found the identity reconstruction challenging and out of their control. The present research showed a negative construction of N-Identity, I-Identity and D-Identity, particularly when data analysis was done considering "The Making Strange Tool" (Tool 3) and "The Subject Tool" (Tool 4).

After a disastrous attack of brain hemorrhage leading to aphasic symptoms, the patient was referred to primary health unit for speech rehabilitation. The very first post-stroke practice was to tag the patient 'aphasic', which usually meant unable to speak. From the very first interaction with the society, the aphasic was forced to dissocialize himself. Subsequently, the patient's N-Identity was recognized and reconstructed as aphasic, because $\mathrm{N}$-Identity can only become identity when it is recognized by that person. For example, the participant $(\mathrm{n}=2)$ was able to produce reasonable verbal output but he had developed his N-Identity as goonga (a dumb person), a negative construction of N-Identity characterized by 12 years of aphasic history. When the participant $(\mathrm{n}=1)$ sang a song while replacing a pronoun "my" with "your", he had recognized his N-Identity as a person nobody needed. This example from the dataset revealed that N-Identity gains its force as identity through the exertion of social context, e.g., institutional, discursive or affinity group dialogues. These forces, in turn, according to Gee (2000), establish other perspectives of identity (Gee, 2000).

When the patients with aphasia, after getting initial treatment and speech therapy, returned to work, they reconstructed their I-Identity, which sought its force from authorities of institution. Contrary to the findings of the research study by Musser et al., (2015) where occupational identity in post-stroke aphasia was positively developed, this study revealed that I-Identity, like N-Identity, was distorted and reconstructed negatively when the participant $(\mathrm{n}=1)$ asked his speech therapist to help him learn counting, otherwise he would be fired (ak, doo, teen yaad...dafter sy nkala) (Musser et al., 2015). Once the patient with aphasia, who was quite active motorically before this disease, was diagnosed as "aphasic" by a speech pathologist and potentially acquired aphasia as an N-Identity, he became a client of a speech rehabilitation institution. In this way, the patient's aphasic N-Identity moves on to constitute an I-Identity.

The patients with aphasia were identified with a role defined by speech rehabilitation practices and medical discourses to aphasia disorder whereby their N-Identity and I-Identity support each other in the wider context. Here, the third perspective of identity i.e., discursive perspective involved in the situation. D-Identity, in the case of patients with aphasia, obtained its power from "rational individuals". As described by Paul Gee (2000), these individuals are those who "treat, talk about, and interact" (Gee, 2000) with the patient and create a discourse of aphasia. Confirming the findings of study by Mackay (2003), the present study revealed that medical ideology and rehabilitation discourse consider patients incompetent and encourage their dependency, which marginalizes them from their important others and families (Mackay, 2003). For example, the participant's $(n=1)$ brother affirmed the prevalent discourse about the aphasia patient when he declared that his brother seldom met with relatives (reshty daron sy kam milta hy). In this scenario, as also discovered by Mackay (2003), the participants of the study reconstructed D-Identity negatively.

D-Identity requires an established discourse to sustain in the context; similarly, I-Identity and even N-Identity also require this type of discourse and dialogue to maintain them. In the presence of such practices, the patients with aphasia try to negotiate and create an affinity group where they are appreciated to develop their A-Identity, which seeks its power from a set of distinctive practices of an affinity group through participation and sharing in terms of culture or traits $(\mathrm{Gee}, 2000)$. In the present research, the data revealed the positive reconstruction of A-Identity, with some exceptions. Consistent with the results of Simmons et al., (2015), which revealed the importance of simultaneous improvement in patient's communication and positive development of identity in group aphasia therapy, the current study also discovered positive construction of A-Identity when the participant $(\mathrm{n}=3)$ projected enthusiasm in making a Facebook group of aphasics (ef be goup bnao). He was identified by the experiences he gained in that specific affinity group. Simmons et al., (2015) achieved these results without 
raising the element of the patient's disability to the surface and without labeling the diagnostic tag and exerting expert authority to them. The participant's contribution as member and participant in their affinity group was of much importance, which was considered an important factor for positive construction of identity. Similar to the results of the present research, positive identity construction evidences were reported in which the participants showed group solidarity or togetherness by appreciating group members' competence and sharing mutual laughter that ensured the existence of group identity constructed within the affinity group. However, it is noticeable that this positivity is only limited to the in-group domains of aphasic patients, whereas the out-groups, including their immediate family members, friends and institutions, deny them the opportunity to create an effective affinity with them.

\section{Conclusion and Limitations}

In this study, the discourse analysis using Paul Gee's Toolkit (2010) proved to be a valuable method of exploring post-stroke negative identity construction in the patients with aphasia. The rigorous consideration to the structure of verbal and nonverbal discourse and reflection of the perceptions and context of the patients allowed the researchers to achieve an insight into different perspectives of identity reconstruction as a process, which is supposed to be embedded in the social context (De Fina, Schiffrin, \& Bamberg, 2006). Through this analysis of social interaction, the researchers were able to view the specific interaction between the participants' linguistic/ paralinguistic behaviors and social worlds, and also the processes underlying identity construction in post-stroke context.

The findings of the study show that the positive identity construction in post-stroke patients is a huge challenge that is directly concerned with the patients themselves, their family members, society and health care services, who/which aim to facilitate the patients. The patients with aphasia having a communicative disorder have less verbal output, and so, less audience. Considering their identity perception issues and communicative disorders, their partners and important others play an important role in verbalizing their thoughts. The positive reconstruction of A-Identity, in few cases, suggests that the patients feel comfortable in their family and affinity group affiliations. This viewpoint is significant for primary health concerns for understanding the care giving perspective of these patients.

The findings of the study suggest that the vicissitudes of post-stroke identity in aphasia span a range of domains in the social context, particularly concerning the health care services, family and friend groups and the workplace context, and require the patients to reconstruct identity focusing more on their affiliation with affinity groups they belong to. This may be achieved by introducing some kinds of aphasia clubs, aphasia tea houses or aphasia café in Pakistan which will provide the aphasia patients with a place where they can have rehabilitation as well as the comfort of affiliation helping them construct positive A-Identity. Similarly, arrangements to develop aphasia groups, virtually, such as Facebook groups and WhatsApp groups, as a strategy for positive construction of their A-Identity and consequently identity construction in general, may support them dealing with primary health care centers, as well as society. The researchers assumed that this positive construction may extend and generalize to other aspects of identity.

This study had some limitations. One of the important limitations was that the sample of the study consisted of only three male participants and no female participants were a part of the study. Although the strategy used for sample collection was convenient sampling but all three participants were the representatives of professional, educated, and middle class. However, being a small sample size, these participants were not the representative of all the patients with aphasia in Lahore, Pakistan, a fact which may skew the results of the study if done on a larger sample set.

\section{Acknowledgments}

The researchers are indebted to the support and the conducive environment provided by the speech therapy institutions, from which the sample subjects were selected for interviews. No less is the contribution of the caregivers and important others, who verbalized the expression of patients with aphasia and offered genuine understanding of their dilemma. Thanks is also due to the Department of English Language and Literature, University of Management and Technology, Lahore, for the provision of the letter to carry out this research and for allowing to set up a project before the drafting of this article. Constructive feedback and suggestion by peers and colleagues also proved invaluable.

\section{References}

Ahlsén, E. (2006). Introduction to neurolinguistics. John Benjamins Publishing.

Ali, N., Rafi, M. S., Khan, M. S. G., \& Mahfooz, U. (2016). Rejuvenating lost communication through script 
training. JPMA. The Journal of the Pakistan Medical Association, 66(12), 1671-1671.

Ali, N., Rafi, M. S., Khan, M. S. G., \& Mahfooz, U. (2018). The effectiveness of script training to restore lost communication in a patient with Broca's aphasia. The Journal of the Pakistan Medical Association, 68(7), 1070-1075.

Bluvol, A. (2003). Quality of life in stroke survivors and their spouses: predictors and clinical implications for rehabilitation teams. Axone, 25(2), 10-19.

Bokhour, B. G., Powel, L. L., \& Clark, J. A. (2007). No less a man: reconstructing identity after prostate cancer. Communication, 4(1), 99-109. https://doi.org/10.1515/CAM.2007.010

Brady, M. C., Kelly, H., Godwin, J., Enderby, P., \& Campbell, P. (2016). Speech and language therapy for aphasia following stroke. The Cochrane Library.

Brown, K., Worrall, L., Davidson, B., \& Howe, T. (2010). Snapshots of success: An insider perspective on living successfully with aphasia. Aphasiology, 24(10), 1267-1295. https://doi.org/10.1080/02687031003755429

Brown, K., Worrall, L., Davidson, B., \& Howe, T. (2015). Exploring speech-language pathologists' perspectives about living successfully with aphasia. International Journal of Language \& Communication Disorders, 1 12.

Cameron, J. I., Cheung, A. M., Streiner, D. L., Coyte, P. C., \& Stewart, D. E. (2011). Stroke survivor depressive symptoms are associated with family caregiver depression during the first 2 years poststroke. Stroke, 42(2), 302-306.

Ch’Ng, A. M., French, D., \& Mclean, N. (2008). Coping with the challenges of recovery from stroke: long term perspectives of stroke support group members. Journal of Health Psychology, 13(8), 1136-1146. https://doi.org/10.1177/1359105308095967

Coombs, U. E. (2007). Spousal caregiving for stroke survivors. Journal of Neuroscience Nursing, 39(2), 112119.

Cooney, A., Murphy, K., \& O’Shea, E. (2009). Resident perspectives of the determinants of quality of life in residential care in Ireland. Journal of Advanced Nursing, 65(5), 1029-1038. https://doi.org/10.1111/j.1365-2648.2008.04960.x

Coppens, P. (2016). Aphasia and related neurogenic communication disorders. Jones \& Bartlett Publishers.

Dalemans, R. J. P., de Witte, L., van den Heuvel, W., \& Wade, D. (2010). Social participation in working age people with aphasia: A review of the literature. Stroke Survivors with Aphasia and Their Social Participation, 17.

Davidson, B., Howe, T., Worrall, L., Hickson, L., \& Togher, L. (2008). Social participation for older people with aphasia: The impact of communication disability on friendships. Topics in Stroke Rehabilitation, 15(4), 325-340. https://doi.org/10.1310/tsr1504-325

De Fina, A., Schiffrin, D., \& Bamberg, M. (2006). Discourse and identity (Vol. 23). Cambridge University Press.

Dickey, L., Kagan, A., Lindsay, M. P., Fang, J., Rowland, A., \& Black, S. (2010). Incidence and profile of inpatient stroke-induced aphasia in Ontario, Canada. Archives of Physical Medicine and Rehabilitation, 91(2), 196-202. https://doi.org/10.1016/j.apmr.2009.09.020

Ekstam, L., Tham, K., \& Borell, L. (2011). Couples' approaches to changes in everyday life during the first year after stroke. Scandinavian Journal of Occupational Therapy, 18(1), 49-58. https://doi.org/10.3109/11038120903578791

Ellis-Hill, C. S., Payne, S., \& Ward, C. (2000). Self-body split: issues of identity in physical recovery following a stroke. Disability and Rehabilitation, 22(16), 725-733. https://doi.org/10.1080/09638280050191990

Emmelhainz, C. (2012). Naming a new self: Identity elasticity and self-definition in voluntary name changes. Names, 60(3), 156-165. https://doi.org/10.1179/0027773812Z.00000000022

Engelter, S. T., Gostynski, M., Papa, S., Frei, M., Born, C., Ajdacic-Gross, V., ... Lyrer, P. A. (2006). Epidemiology of aphasia attributable to first ischemic stroke: incidence, severity, fluency, etiology, and thrombolysis. Stroke, 37(6), 1379-1384.

Eriksson, M., \& Svedlund, M. (2006). 'The intruder': spouses' narratives about life with a chronically ill partner. Journal of Clinical Nursing, 15(3), 324-333. https://doi.org/10.1111/j.1365-2702.2006.01290.x 
Gee, J. P. (2000). Chapter 3: Identity as an analytic lens for research in education. Review of Research in Education, 25(1), 99-125. https://doi.org/10.3102/0091732X025001099

Gee, J. P. (2010). How to do discourse analysis: A toolkit. Routledge.

Golub, S. A., Rendina, H. J., \& Gamarel, K. E. (2013). Identity-related growth and loss in a sample of HIV-positive gay and bisexual men: initial scale development and psychometric evaluation. AIDS and Behavior, 17(2), 748-759.

Goodwin, C. (1987). Forgetfulness as an interactive resource. Social Psychology Quarterly, 115-130.

Greenhalgh, T., \& Goozner, M. (2017). What seems to be the trouble?: stories in illness and healthcare. CRC Press.

Grigorovich, A., Forde, S., Levinson, D., Bastawrous, M., Cheung, A. M., \& Cameron, J. I. (2015). Restricted participation in stroke caregivers: who is at risk? Archives of Physical Medicine and Rehabilitation, 96(7), 1284-1290. https://doi.org/10.1016/j.apmr.2015.03.004

Guina, J., \& Guina, C. (2018). Wants Talk Psychotherapy but Cannot Talk: EMDR for Post-stroke Depression with Expressive Aphasia. Innovations in Clinical Neuroscience, 15(1-2), 45.

Hallé, M.-C., Duhamel, F., \& Le Dorze, G. (2011). The daughter-mother relationship in the presence of aphasia: How daughters view changes over the first year poststroke. Qualitative Health Research, 21(4), 549-562. https://doi.org/10.1177/1049732310391274

Hilari, K., Needle, J. J., \& Harrison, K. L. (2012). What are the important factors in health-related quality of life for people with aphasia? A systematic review. Archives of Physical Medicine and Rehabilitation, 93(1), S86-S95. https://doi.org/10.1016/j.apmr.2011.05.028

Howe, T. (2017). Found opportunities for social participation: Facilitating inclusion of adults with aphasia. Topics in Language Disorders, 37(1), 38-51. https://doi.org/10.1097/TLD.0000000000000113

Howe, T., Davidson, B., Worrall, L., Hersh, D., Ferguson, A., Sherratt, S., \& Gilbert, J. (2012). 'You needed to rehab... families as well': family members' own goals for aphasia rehabilitation. International Journal of Language \& Communication Disorders, 47(5), 511-521. https://doi.org/10.1111/j.1460-6984.2012.00159.x

Husbands, S., Jowett, S., Barton, P., \& Coast, J. (2017). How Qualitative Methods Can be Used to Inform Model Development. PharmacoEconomics, 35(6), 607-612.

Khalid, W., Rozi, S., Ali, T. S., Azam, I., Mullen, M. T., Illyas, S., ... Kamal, A. K. (2016). Quality of life after stroke in Pakistan. BMC Neurology, 16(1), 250. https://doi.org/10.1186/s12883-016-0774-1

Kim, K., Kim, Y. M., \& Kim, E. K. (2014). Correlation between the activities of daily living of stroke patients in a community setting and their quality of life. Journal of Physical Therapy Science, 26(3), 417-419. https://doi.org/10.1589/jpts.26.417

Lapadatu, I., \& Morris, R. (2017). The relationship between stroke survivors' perceived identity and mood, self-esteem and quality of life. Neuropsychological Rehabilitation, 1-15. https://doi.org/10.1080/09602011.2016.1272468

Laska, A. C., Hellblom, A., Murray, V., Kahan, T., \& Von Arbin, M. (2001). Aphasia in acute stroke and relation to outcome. Journal of Internal Medicine, 249(5), 413-422. https://doi.org/10.1046/j.1365-2796.2001.00812.x

Law, J., Rush, R., Pringle, A.-M., Irving, A.-M., Huby, G., Smith, M., ... Burston, A. (2009). The incidence of cases of aphasia following first stroke referred to speech and language therapy services in Scotland. Aphasiology, 23(10), 1266-1275. https://doi.org/10.1080/02687030802514953

Maaijwee, N. A., Rutten-Jacobs, L. C., Arntz, R. M., Schaapsmeerders, P., Schoonderwaldt, H. C., van Dijk, E. J., \& de Leeuw, F.-E. (2014). Long-term increased risk of unemployment after young stroke A long-term follow-up study. Neurology, 83(13), 1132-1138. https://doi.org/10.1212/WNL.0000000000000817

Maas, M. B., Lev, M. H., Ay, H., Singhal, A. B., Greer, D. M., Smith, W. S., ... Furie, K. L. (2012). The prognosis for aphasia in stroke. Journal of Stroke and Cerebrovascular Diseases, 21(5), 350-357. https://doi.org/10.1016/j.jstrokecerebrovasdis.2010.09.009

Mackay, R. (2003). 'Tell them who i was'[1]: the social construction of aphasia. Disability \& Society, 18(6), 811-826. https://doi.org/10.1080/0968759032000119532

Manning, M., Hickey, A., MacFarlane, A., \& Franklin, S. (2017). Perspectives of people with aphasia 
post-stroke towards recovery $\&$ living successfully. A systematic review and qualitative evidence synthesis. International Journal of Integrated Care, 17(5).

Mansur, L. L., Radanovic, M., Rüegg, D., Mendonça, L. I. Z. de, \& Scaff, M. (2002). Descriptive study of 192 adults with speech and language disturbances. Sao Paulo Medical Journal, 120(6), 170-174. http://dx.doi.org/10.1590/S1516-31802002000600003

Muenchberger, H., Kendall, E., \& Neal, R. (2008). Identity transition following traumatic brain injury: A dynamic process of contraction, expansion and tentative balance. Brain Injury, 22(12), 979-992. https://doi.org/10.1080/02699050802530532

Musser, B., Wilkinson, J., Gilbert, T., \& Bokhour, B. G. (2015). Changes in identity after aphasic stroke: implications for primary care. International Journal of Family Medicine, 2015. http://dx.doi.org/10.1155/2015/970345

Persson, J. (2017). Spouses long-term support to midlife stroke survivors-Consequences in a health economic perspective.

Pike, C., Kritzinger, A., \& Pillay, B. (2017). Social participation in working-age adults with aphasia: an updated systematic review. Topics in Stroke Rehabilitation, 24(8), 627-639. https://doi.org/10.1080/10749357.2017.1366012

Plowman, E., Hentz, B., \& Ellis, C. (2012). Post-stroke aphasia prognosis: A review of patient-related and stroke-related factors. Journal of Evaluation in Clinical Practice, 18(3), 689-694. https://doi.org/10.1111/j.1365-2753.2011.01650.x

Pound, C., Duchan, J., Penman, T., Hewitt, A., \& Parr, S. (2007). Communication access to organisations: Inclusionary practices for people with aphasia. Aphasiology, 21(1), 23-38. https://doi.org/10.1080/02687030600798212

Qamar, Z. K. (2012). Depression among stroke patients and relation with demographic and stroke characteristics (PhD Thesis). Umela a International School of Public Health.

Shadden, B. (2005). Aphasia as identity theft: Theory and practice. Aphasiology, 19(3-5), 211-223. https://doi.org/10.1080/02687930444000697

Shadden, B. B., \& Agan, J. P. (2004). Renegotiation of identity: The social context of aphasia support groups. Topics in Language Disorders, 24(3), 174-186.

Shyu, Y.-I. L., Maa, S.-H., Chen, S.-T., \& Chen, M.-C. (2009). Quality of life among older stroke patients in Taiwan during the first year after discharge. Journal of Clinical Nursing, 18(16), 2320-2328. https://doi.org/10.1111/j.1365-2702.2008.02458.x

Sorin-Peters, R. (2003). Viewing couples living with aphasia as adult learners: Implications for promoting quality of life. Aphasiology, 17(4), 405-416. https://doi.org/10.1080/02687030244000752

Teasell, R. W., McRae, M. P., \& Finestone, H. M. (2000). Social issues in the rehabilitation of younger stroke patients. Archives of Physical Medicine and Rehabilitation, 81(2), 205-209. https://doi.org/10.1016/S0003-9993(00)90142-4

Thomas, S. A., \& Lincoln, N. B. (2008). Predictors of emotional distress after stroke. Stroke, 39(4), 1240-1245.

Wahrborg, P. (2008). Assessment and management of emotional and psychosocial reactions to brain damage and aphasia. John Wiley \& Sons.

Walder, K., \& Molineux, M. (2017). Re-establishing an occupational identity after stroke-a theoretical model based on survivor experience. British Journal of Occupational Therapy, 80(10), 620-630. https://doi.org/10.1177/0308022617722711

Walker, W. (2007). Ethical considerations in phenomenological research. Nurse Researcher, 14(3), 36-45.

Wolfenden, B., \& Grace, M. (2009). Returning to work after stroke: a review. International Journal of Rehabilitation Research, 32(2), 93-97.

\section{Copyrights}

Copyright for this article is retained by the author, with first publication rights granted to the journal.

This is an open-access article distributed under the terms and conditions of the Creative Commons Attribution license (http://creativecommons.org/licenses/by/4.0/). 